\title{
From Strict Glycemic Control to Improving Cardiovascular Outcomes: A Shift in the Management Strategies for Type 2 Diabetes
}

\author{
May Mak ${ }^{1 *}$, Esther $\mathrm{Im}^{2}$ and Vladimir Kozhemyakin ${ }^{2}$ \\ ${ }^{1}$ Department of Pharmacy Practice, Chapman University, USA \\ ${ }^{2}$ Department of Pharmacy Practice, Chapman University, USA
}

*Corresponding author: May Mak, Department of Pharmacy Practice, Chapman

University, USA.

\begin{abstract}
Newer classes of agents targeted to enhance glycemic control have been the focus of attention for their demonstrated reduction of cardiovascular (CV) events. In the latest 2020 American Diabetes Association (ADA) Standards of Medical Care in Diabetes, specific recommendations are made regarding improvement of $\mathrm{CV}$ outcomes in patients with diabetes. For those patients with type 2 diabetes (T2DM) who have established atherosclerotic cardiovascular disease (ASCVD) or indicators of high-risk for CVD, established kidney disease, or heart failure (HF), a sodium-glucose cotransporter 2 inhibitor (SGLT2i) or glucagon-like peptide 1 receptor agonist (GLP-1 RA) with demonstrated CV benefits can be recommended as part of the regimen independent of glycosylated hemoglobin (HgbA1c) while considering patient-specific factors. In addition, for patients with T2DM who need to achieve better control than with existing oral medications, GLP-1 RAs are preferred to insulin, when feasible. Similar to the ADA recommendation, the 2020 Management Algorithm from American Association of Clinical Endocrinologists (AACE) \& American College of Endocrinology (ACE) also suggests the addition of a GLP-1 RA or SGLT2i independent of glycemic control, if there is established ASCVD or high risk for CVD, chronic kidney disease (CKD), or reduced ejection heart failure.

This review aims to interpret the CV outcomes demonstrated for the SGLT2i and GLP-1 RA agents that currently have FDA approved indications for reduction of risk of major adverse cardiovascular events (MACE) in T2DM patients with established CVD or CV risks. The information in this article will suggest overlapping effects on the heart, kidney while achieving glycemic control.
\end{abstract}

\section{Background}

Recent report from the U.S. Food and Drug Administration (FDA) estimates that more than 30 million Americans have diabetes, and $90 \%$ to $95 \%$ of them have type 2 diabetes (T2DM). This group of population can suffer from short- and long-term complications, including microvascular damage to the nerves, kidneys, and eyes; as well as macrovascular consequences that may increase the risks of sleep apnea, heart and blood vessel diseases [1]. The high morbidity and mortality rate caused by cardiovascular (CV) diseases have long been recognized, and now improving CV outcomes is becoming a focus in managing diabetes along with glycemic control.

In 2008, the FDA issued a Guidance for Industry stating that all new T2DM drug development programs should rule out unacceptable cardiovascular risk by demonstrating an upper bound of the two-sided $95 \%$ confidence interval (CI) of the risk ratio $<1.8$ pre-approval for a composite end point of major adverse cardiac events (MACE), consisting of at least cardiovascular death, nonfatal myocardial (MI) infarction, and stroke. If the upper CI lies between 1.3 to 1.8 , then a post-marketing CV trial is usually required to demonstrate the $\mathrm{CI}$ to be $<1.3$. However, in practice, each sponsor of recently approved drugs has followed this guidance, making post-marketing CV studies almost obligatory [2]. These FDA recommendations stemmed from previous concerns over high prevalence of cardiovascular disease (CVD) in diabetes, possibly contributed by conventional pharmacologic agents used to achieve glycemic control. Based on historical data, sulfonylureas are associated with a higher all-cause mortality, CV 
mortality, composite incidence of myocardial infarction, and stroke compared to other diabetes medications. As a result, the class of sulfonylurea medications carries a "black box" CV warning from the FDA regarding heightened risk for CV events. Earlier implications associating the thiazolidinediones with fluid retention, heart failure, and bladder cancer have also led to reduced use of these agents. Although the MI risks for rosiglitazone have been largely dispelled and pioglitazone showing net CV benefits, the concern of heart failure risk, in addition to weight gain and potential risks for bone fractures, continue to limit the wide use of these agents in recent years.

More recently, cardiovascular outcome trials (CVOTs) have shown cardiovascular safety with the class of dipeptidyl peptidase- 4 inhibitors (DPP-4 inhibitors), but they have not demonstrated net $\mathrm{CV}$ benefits. More recent data, however, suggested a higher risk of heart failure with the use of sitagliptin and alogliptin. As a result, FDA issued warnings of the potential of heart failure and its exacerbation while on these agents. Patients are urged to contact their physicians if they experience increasing shortness of breath, unusually fast increase in weight, swelling or fluid retention, and unusual tiredness [3]. Newer classes of agents targeted to enhance glycemic control have been the focus of attention for their demonstrated reduction of cardiovascular (CV) events. In the latest 2020 American Diabetes Association (ADA) Standards of Medical Care in Diabetes, specific recommendations are made regarding improvement of $\mathrm{CV}$ outcomes in patients with diabetes. Among these recommendations is a patient-centered approach with therapeutic considerations for CV comorbidities. For those patients with type 2 diabetes (T2DM) who have established atherosclerotic cardiovascular disease (ASCVD) or indicators of high-risk for CVD, established kidney disease, or heart failure (HF), a sodium-glucose cotransporter 2 inhibitor (SGLT2i) or glucagonlike peptide 1 receptor agonist (GLP-1 RA) with demonstrated CV benefits can be recommended as part of the regimen independent of glycosylated hemoglobin (HgbA1c) while considering patientspecific factors. In addition, for patients with T2DM who need to achieve better control than with existing oral medications, GLP-1 RAs are preferred to insulin, when feasible [4]. Similar to the ADA recommendation, the 2020 Management Algorithm from American Association of Clinical Endocrinologists (AACE) \& American College of Endocrinology (ACE) also suggests the addition of a GLP-1 RA or SGLT2i independent of glycemic control, if there is established ASCVD or high risk for CVD, chronic kidney disease (CKD), or reduced ejection heart failure [5].

The following sections summarize the positive CV outcomes demonstrated for agents that currently have FDA approved indications for reduction of risk of major adverse cardiovascular events (MACE) in T2DM patients with established CVD or CV risks. Other agent-specific approved indications include reduction of risk of end stage renal disease (ESRD), doubling of serum creatinine, and hospitalization for heart failure (hHF) in those with T2DM and DM nephropathy with albuminuria $>300 \mathrm{mg} /$ day.

\section{Sodium-glucose Cotransporter 2 Inhibitors}

Currently, three of the four SGLT2 inhibitors on the market have FDA approved labelling for CV benefits in addition to improving glycemic control as an adjunct therapy. Empagliflozin is indicated to reduce the risk of $\mathrm{CV}$ death in adults with T2DM and established CVD [6]. Dapagliflozin is indicated to reduce the risk of hHF in adults with T2DM and established CVD or multiple CV risk factors [7]. Canagliflozin is indicated to reduce the risk of MACE in adults with T2DM and established CVD as well as to reduce the risk of ESRD, doubling of serum creatinine, CV death, and hHF in adults with T2DM and diabetic nephropathy with albuminuria [8] (Table 1). The Empagliflozin, Cardiovascular Outcomes, and Mortality in Type 2 Diabetes (EMPA-REG OUTCOME) trial highlights the effects of empagliflozin in CV morbidity and mortality when compared to placebo. This trial enrolled 7,020 participants for a median duration of 3.1 years. The primary hypothesis of the EMPA-REG OUTCOME trial was noninferiority for the primary outcome with empagliflozin. In adult patients with T2DM, eGFR of $30 \mathrm{~mL} /$ $\min / 1.73 \mathrm{~m}^{2}$ or greater, and established CV disease, empagliflozin was shown to have superiority over placebo, resulting in a lower rate of primary composite CV outcomes (including CV death, nonfatal MI, or nonfatal stroke), when added to standard care. However, empagliflozin did not show a significant difference compared to placebo for individual outcomes of MI or stroke. For the secondary composite CV outcomes, including hospitalization for unstable angina, empagliflozin was shown to be non-inferior to placebo, with limited evidence in superiority. There was more genital infection reported in the empagliflozin group than placebo, but overall, there was no significant difference in the two study groups in adverse events. This study concluded that empagliflozin, as compared to placebo, had a lower rate of the primary composite $\mathrm{CV}$ outcome and of death from any cause when it was added to standard care in patients with T2DM at high risk for CV events [9].

Table 1: Cardiovascular Outcome Trials for Sodium-glucose Cotransporter 2 Inhibitors.

\begin{tabular}{|c|c|c|c|c|}
\hline Trial & $\begin{array}{l}\text { EMPA-REG9(Empagliflozin) } \\
\qquad \mathrm{N}=7,020\end{array}$ & $\begin{array}{c}\text { CANVAS10 (Canagliflozin) } \\
\qquad \mathrm{N}=9,734\end{array}$ & $\begin{array}{l}\text { CREDENCE11 (Canagliflozin) } \\
\qquad \mathrm{N}=4,401\end{array}$ & $\begin{array}{l}\text { DECLARE12 } \\
\text { (Dapagliflozin) } \\
\mathrm{N}=17,160\end{array}$ \\
\hline \multirow{2}{*}{$\begin{array}{l}\text { Inclusion Criteria } \\
\text { (T2D) }\end{array}$} & $\begin{array}{l}\text { Hgb A1c } 7-9 \% \text { o No glucose- } \\
\text { lowering agent for } \geq 12 \text { weeks before } \\
\text { randomization }\end{array}$ & Hgb A1c 7-10.5\% & Hgb A1c 6.5-12\% & Hgb A1c $6.5-12 \%$ \\
\hline & $\begin{array}{l}\text { Hgb A1c } 7-10 \% \text { o Received stable } \\
\text { glucose lowering agents for } \geq 12 \\
\text { weeks before randomization }\end{array}$ & $\begin{array}{l}\text { Age } \geq 30 \text { years with a } \\
\text { history of symptomatic } \\
\text { atherosclerotic CV disease }\end{array}$ & Age $\geq 30$ years & Age $\geq 40$ years \\
\hline
\end{tabular}




\begin{tabular}{|c|c|c|c|c|}
\hline & - Age $>18$ years & $\begin{array}{l}-\geq 50 \text { years with two or } \\
\text { more risk factors for CVD }\end{array}$ & $\begin{array}{l}\text { - eGFR } 30-89 \mathrm{~mL} / \\
\min / 1.73 \mathrm{~m} 2\end{array}$ & $\begin{array}{l}\text { High risk of CV events } \\
\text { (established CVD and/or } \\
\text { multiple risk factors) }\end{array}$ \\
\hline & - BMI $\leq 45$ & $\begin{array}{l}\text { - eGFR }>30 \mathrm{~mL} / \\
\mathrm{min} / 1.73 \mathrm{~m} 2\end{array}$ & - UACR 301-5000 mg/g & - $\mathrm{CrCl}>60 \mathrm{~mL} / \mathrm{min}$ \\
\hline & - eGFR $\geq 30 \mathrm{~mL} / \mathrm{min} / 1.73 \mathrm{~m} 2$ & & $\begin{array}{l}\text { Stable maximum tolerated } \\
\text { labeled daily dose of ACEi or } \\
\text { ARB for } \geq 4 \text { weeks }\end{array}$ & \\
\hline & - Established CVD & & & \\
\hline \multirow[t]{5}{*}{ Pt Characteristics } & - Average age: 63.1 years & - Average age: 63.3 years & Average age: 62.9 years & $\begin{array}{l}\text { Average age: } 63.9 \\
\text { years }\end{array}$ \\
\hline & - Race: White (72.6\%) & - Race: White (77.8\%) & - Race: White (67.5\%) & - Race: White (79.7\%) \\
\hline & - Sex: Male (71.2\%) & Sex: Male $(64.9 \%)$ & - Sex: Male (65.4\%) & Sex: Male (63.1\%) \\
\hline & - Baseline established CVD (99.4\%) & $\begin{array}{l}\text { - Baseline established CVD } \\
(64.8 \%)\end{array}$ & $\begin{array}{l}\text { - Baseline established CVD } \\
\text { (50.5\%) }\end{array}$ & $\begin{array}{l}\text { - Baseline established } \\
\text { CVD }(40.5 \%)\end{array}$ \\
\hline & - Mean eGFR 74.4 & - Mean eGFR 76.7 & - Mean eGFR 56.3 & - Mean eGFR 85.4 \\
\hline Duration & 3.1 years & 3.6 years & 2.6 years & 4.2 years \\
\hline Baseline, End A1c & $8.1 \%, 7.7 \%$ & $8.2 \%, 8.0 \%$ & $8.3 \%, 7.9 \%$ & $8.3 \%, 7.9 \%$ \\
\hline Intervention & $\begin{array}{c}\text { Empagliflozin } 10 \mathrm{mg} \text { or } 25 \mathrm{mg} \text { PO } \\
\text { daily }\end{array}$ & $\begin{array}{l}\text { CANVAS: Canagliflozin } 100 \\
\text { mg or } 300 \text { mg PO daily } \\
\text { CANVAS-R: Canagliflozin } \\
100 \text { mg with an optional } \\
\text { increase to } 300 \mathrm{mg} \text { starting } \\
\text { from week } 13\end{array}$ & Canagliflozin 100 mg PO daily & $\begin{array}{l}\text { Dapagliflozin } 10 \text { mg PO } \\
\text { daily }\end{array}$ \\
\hline \multirow[t]{4}{*}{$\begin{array}{c}\text { Primary } \\
\text { composite } \\
\text { endpoint: (agent } \\
\text { vs placebo) } \\
\end{array}$} & $\begin{array}{l}\text { CV mortality, nonfatal MI, or nonfatal } \\
\text { stroke }\end{array}$ & $\begin{array}{l}\text { CV mortality, nonfatal MI, or } \\
\text { nonfatal stroke }\end{array}$ & $\begin{array}{l}\text { ESRD, doubling of baseline } \\
\text { serum creatinine, renal } \\
\text { mortality, or cardiovascular } \\
\text { mortality }\end{array}$ & $\begin{array}{l}\text { Cardiovascular death or } \\
\text { hospitalization for heart } \\
\text { failure }\end{array}$ \\
\hline & $\begin{array}{c}13.0 \% \text { vs } 14.9 \% \text { (HR } 0.87 ; 95 \% \text { CI } \\
0.78-0.97 ; \mathrm{P}=0.01 \text { ) }\end{array}$ & $\begin{array}{c}\text { 6.6\% vs } 8.9 \% \text { (HR } 0.74 \\
95 \% \text { CI } 0.58-0.95 ; \mathrm{P}<0.001 \text { ) }\end{array}$ & $\begin{array}{l}12.0 \% \text { vs } 13.4 \% \text { (HR } 0.88 ; 95 \% \\
\quad \text { CI } 0.79-0.99 ; \mathrm{P}=0.026 \text { ) }\end{array}$ & $\begin{array}{c}4.9 \% \text { vs } 5.8 \% \text { (HR } \\
0.83 ; 95 \% \text { CI 0.73-0.95; } \\
\text { P=0.005) }\end{array}$ \\
\hline & & & $\begin{array}{c}\text { Doubling of baseline serum } \\
\text { creatinine } 5.4 \% \text { vs } 8.5 \% \\
\text { (HR 0.60; } 95 \% \text { CI } 0.48-0.76 \text {; } \\
\text { P<0.001 }\end{array}$ & \\
\hline & & & $\begin{array}{l}\text { ESRD 5.3\% vs 7.5\% (HR 0.68; } \\
\text { 95\% CI 0.54-0.86; P=0.002 }\end{array}$ & \\
\hline $\begin{array}{c}\text { Secondary } \\
\text { endpoint: CV } \\
\text { death (agent vs } \\
\text { placebo) }\end{array}$ & $\begin{array}{c}3.7 \% \text { vs } 5.9 \% \text { (HR } 0.62 ; 95 \% \text { CI } 0.49- \\
0.77 ; P=0.001)\end{array}$ & $\begin{array}{c}11.6 \text { vs } 12.8 \text { per } 1000 \\
\text { patient-yrs (HR } 0.87 ; 95 \% \\
\text { CI } 0.72-1.06 ; \mathrm{P}=0.9387 \text { ) }\end{array}$ & $\begin{array}{c}5.0 \% \text { vs } 6.4 \%(\mathrm{HR} 0.78 ; 95 \% \mathrm{CI} \\
0.61-1.00 ; \mathrm{P}=0.05)\end{array}$ & $\begin{array}{c}\text { 2.9\% vs } 2.9 \% \text { (HR } 0.98 \\
\text { 95\% CI 0.82-1.17, no } \\
\text { P-value) }\end{array}$ \\
\hline $\begin{array}{c}\text { Secondary } \\
\text { endpoint: Stroke } \\
\text { (agent vs placebo) }\end{array}$ & $\begin{array}{c}3.2 \% \text { vs } 2.6 \% \text { (HR } 1.24 ; 95 \% \text { CI } 0.92- \\
1.67 ; \mathrm{P}=0.16 \text { ) }\end{array}$ & $\begin{array}{l}7.1 \text { vs } 8.4 \text { per } 1000 \text { patient- } \\
\text { yrs (HR 0.90; } 95 \% \text { CI } 0.71- \\
1.15 ; P=0.4978 \text { ) }\end{array}$ & N/A & $\begin{array}{c}\text { 2.7\% vs } 2.7 \% \text { (HR } 1.01 ; \\
95 \% \text { CI 0.84-1.21; no } \\
\text { P-value) }\end{array}$ \\
\hline $\begin{array}{c}\text { Secondary } \\
\text { endpoint: HF } \\
\text { hospitalization } \\
\text { (agent vs placebo) }\end{array}$ & $\begin{array}{c}2.7 \% \text { vs } 4.1 \% \text { (HR } 0.65 ; 95 \% \text { CI } 0.50- \\
0.85 ; P=0.002 \text { ) }\end{array}$ & $\begin{array}{c}\text { (HR } 5.5 \text { vs } 8.7 \text { per } 1000 \\
\text { patient-yrs } 0.67 ; 95 \% \text { CI } \\
0.52-0.87 ; \mathrm{P}=0.2359 \text { ) }\end{array}$ & $\begin{array}{c}4.0 \% \text { vs } 6.4 \%(\mathrm{HR} 0.61 ; 95 \% \mathrm{CI} \\
0.47-0.80 ; \mathrm{P}<0.001)\end{array}$ & $\begin{array}{c}\text { 2.5\% vs } 3.3 \% \text { (HR } 0.73 ; \\
95 \% \text { CI 0.61-0.88); no } \\
\text { P-value) }\end{array}$ \\
\hline $\begin{array}{c}\text { Secondary } \\
\text { endpoint: } \\
\text { Nephropathy } \\
\text { (agent vs placebo) }\end{array}$ & N/A & $\begin{array}{c}89.4 \text { vs } 128.7 \text { per } 1000 \\
\text { patient-yrs (HR } 0.73 ; 95 \% \\
\text { CI } 0.67-0.79 ; \mathrm{P}=0.0184 \text { ) } \\
\text { *Progression of albuminuria }\end{array}$ & $\begin{array}{l}6.9 \% \text { vs } 10.2 \% \text { (HR } 0.66 ; 95 \% \\
\quad \text { CI } 0.53-0.81 ; \mathrm{P}<0.001)\end{array}$ & $\begin{array}{c}\text { 1.5\% vs } 2.8 \% \text { (HR } 0.53 ; \\
95 \% \text { CI 0.43-0.66; no } \\
\text { P-value) }\end{array}$ \\
\hline \multirow{2}{*}{$\begin{array}{l}\text { Other adverse } \\
\text { effects (agent vs } \\
\text { placebo) }\end{array}$} & \multirow{2}{*}{$\begin{array}{c}\text { Genital Infection: } 6.4 \% \text { vs } 1.8 \% \text { no } \\
\text { P-value }\end{array}$} & \multirow{2}{*}{$\begin{array}{c}\text { Amputation: } 6.3 \text { vs } 3.4 \\
\text { participants per } 1000 \\
\text { patient-yrs } \mathrm{P}<0.001\end{array}$} & \multirow{2}{*}{$\begin{array}{l}\text { P-value was not provided for } \\
\text { adverse effects }\end{array}$} & $\begin{array}{c}\text { DKA: } 0.3 \% \text { vs } 0.1 \% \text { (HR } \\
2.18 ; 95 \% \text { CI } 1.10-4.30 ; \\
P=0.02)\end{array}$ \\
\hline & & & & $\begin{array}{l}\text { Genital infection: } 0.9 \% \\
\text { vs } 0.1 \% \text { (HR } 8.36 ; 95 \% \\
\text { CI } 4.19-16.68 ; \mathrm{P}<0.001)\end{array}$ \\
\hline
\end{tabular}




\begin{tabular}{|c|c|c|c|c|}
\hline $\begin{array}{l}\text { Authors' } \\
\text { Conclusion }\end{array}$ & $\begin{array}{l}\text { Patients with T2DM and high risk } \\
\text { for CV events had a lower rate of } \\
\text { the primary composite CV outcome } \\
\text { and of death from any cause when } \\
\text { empagliflozin was added to standard } \\
\text { care }\end{array}$ & $\begin{array}{l}\text { Patients with T2DM and } \\
\text { an elevated risk of CVD } \\
\text { had a lower risk of CV } \\
\text { events when treated } \\
\text { with canagliflozin, but a } \\
\text { greater risk of amputation, } \\
\text { primarily at the level of the } \\
\text { toe or metatarsal }\end{array}$ & $\begin{array}{l}\text { Patients with T2DM and } \\
\text { kidney disease had a lower } \\
\text { risk of kidney failure and CV } \\
\text { events when treated with } \\
\text { canagliflozin }\end{array}$ & $\begin{array}{l}\text { Patients with T2DM who } \\
\text { had or were at risk for } \\
\text { ASCVD did not have a } \\
\text { higher or lower rate of } \\
\text { MACE, but did result in } \\
\text { a lower rate of CV death } \\
\text { or hHF, a finding that } \\
\text { reflects a lower rate of } \\
\text { hospitalization for HF }\end{array}$ \\
\hline
\end{tabular}

The Canagliflozin and Cardiovascular and Renal Events in Type 2 Diabetes (CANVAS) program integrated data from two sister trials -- CANVAS and CANVAS-R, evaluated the cardiovascular, renal, and safety outcomes of canagliflozin when compared to placebo. Similar to the EMPA-REG OUTCOME trial, the primary hypothesis of the CANVAS trial was also to determine the noninferiority for the primary outcome: composite of death from CV causes, nonfatal MI, or nonfatal stroke. Reported data was compiled from 9,734 participants who were followed for 188.2 weeks. In adult patients with T2DM, mean age of 63.3 years, eGFR greater than $30 \mathrm{~mL} /$ $\mathrm{min} / 1.73 \mathrm{~m} 2$, and established CV disease or elevated risk of CVD, canagliflozin was shown to have a significantly lower rate of the primary composite outcome. There was no difference between the two groups in secondary endpoints, however, fewer patients had progression of albuminuria in the canagliflozin group than the placebo group. A significant finding from this study was the higher risk of amputation of toes or foot in the canagliflozin group than with the placebo group. The authors of the CANVAS program concluded that canagliflozin had a lower risk of CV events, but a greater risk of amputation than placebo in T2DM patients with an elevated risk of CV disease [10].

The Canagliflozin and Renal Outcomes in Type 2 Diabetes and Nephropathy (CREDENCE) trial evaluated the renal effects of canagliflozin in patients with T2DM and albuminuric CKD. Reported data was extracted from 4,401 participants who had a median follow-up of 2.62 years. Participants were adult patients with T2DM, mean age of 63 years, eGFR of $\geq 30$ to $<90$ (mean of 56.2) $\mathrm{mL} / \mathrm{min} / 1.73 \mathrm{~m} 2$, urinary albumin creatinine ratio (UACR) $>300$ to $\leq 5000$ (mean of 927) $\mathrm{mg} / \mathrm{g}$, and established CVD or elevated risk of CVD. The primary composite outcome, which included ESRD, doubling of the serum creatinine level or renal/CV death, was significantly lower in the canagliflozin group than in the placebo group. From the individual outcomes under the primary composite result, canagliflozin was shown to have a significantly lower rate of doubling of serum creatinine level and ESRD than the placebo group. In addition, specific secondary outcomes such as CV death or hospitalization for heart failure (hHF), and renal composite outcome of ESRD, doubling of SCr, or renal death were also lower in the canagliflozin than the placebo group. Safety outcomes were similar between the two study groups. The authors concluded that there was a lower risk of kidney failure and CV events in patients who received canagliflozin compared to placebo in the study population. These results suggest that canagliflozin may be an effective treatment for renal and CV protection in patients with T2DM and CKD [11].
The Dapagliflozin and Cardiovascular Outcomes in Type 2 diabetes (DECLARE-TIMI 58) trial evaluated the safety and efficacy outcomes of dapagliflozin in patients with T2DM who had or were at risk for atherosclerotic CV disease. Reported data was gathered from 17,160 participants who were followed for a median of 4.2 years. The primary efficacy outcomes included MACE and a composite of CV death or hHF. In adult patients with T2DM, mean age of 63.9 years, established CVD (41\%) or multiple risk factors (59\%), and a mean eGFR of $85.4 \mathrm{~mL} / \mathrm{min} / 1.73 \mathrm{~m} 2$, the dapagliflozin group did not have a lower rate of MACE, but had a lower rate of composite outcome for CV death or hHF. Dapagliflozin did not demonstrate any difference from placebo, in respect to secondary outcomes, which included a renal composite (either $40 \%$ or more decrease in eGFR to $<60 \mathrm{ml} / \mathrm{min} / 1.73 \mathrm{~m} 2$, new ESRD, or death from renal or CV cause) and death from any cause. While diabetic ketoacidosis was more common in the dapagliflozin group, the rate of genital infection was significantly higher in patients who received dapagliflozin than those taking placebo. Based on these results, the authors concluded that treatment with dapagliflozin resulted in a lower rate of $\mathrm{CV}$ death or $\mathrm{hHF}$, a finding that reflects a lower rate of hospitalization for heart failure [12].

Although CV benefits in patients with T2DM were demonstrated in these trials, there were also limitations. In the EMPA-REG OUTCOME trial, 99\% of patients had established CVD, therefore making the benefit of empagliflozin in T2DM patients without a history of CVD uncertain. Due to the established CVD, patients in this trial were also well treated with use of renin-angiotensinaldosterone system inhibitors, statins, and acetylsalicylic acid. Therefore, the CV benefits from empagliflozin may be multidimensional, possibly including positive changes such as arterial stiffness, cardiorenal effects, blood pressure, glycemic control, etc. All the other trials (CANVAS, CREDENCE, DECLARETIMI 58) had more balanced number of patients with established CVD and high risk of CVD, which may reflect better applicability of canagliflozin and dapagliflozin to either primary or secondary CVD prevention. However, this may also be interpreted as having a "diluted" CV benefits from these agents [9].

A major limitation of the CANVAS program is the relatively small proportion of participants with established kidney disease. This might have limited its generalization to that particular population. Moreover, there was a greater use of other glucose-lowering agents in the placebo group, which may indicate an underestimation of any benefits and risks associated with canagliflozin [10]. While the CREDENCE trial dispelled the concern of paucity of ESRD events in 
the CANVAS program and included a population with high risk of CV events, it might have overestimated the effect sizes when the trial was stopped early at a planned interim analysis. The CREDENCE trial was also flawed by not having off-treatment eGFR levels measured in patients who had completed the trial, so the differences in eGFR compared to the placebo group might have been under-estimated. In addition, the study did not include patients who had very advanced kidney disease, non-albuminuric or micro-albuminuric disease, and kidney diseases not due to T2DM. Therefore, its findings cannot be generalized to those populations [11]. Compared to other trials, the DECLARE-TIMI 58 had a more restrictive exclusion criteria of creatinine clearance of $<60 \mathrm{~mL} / \mathrm{min}$, which might have limited the demonstration of mortality benefit in patients with poorer kidney function [12]. Finally, all four trials also had concentrated data from the white and male population, therefore it is unknown whether this study limits the external validity in patients who may benefit from a SGLT2-inhibitor, especially in different races or the female population.

\section{Glucagon-like Peptide 1 Receptor Agonists}

At this time, three of the five GLP1 receptor agonists on the market have FDA approved indications to reduce the risk of MACE in adults with T2DM and established CVD in addition to improve glycemic control as an adjunct therapy. In addition to the indication for MACE reduction, dulaglutide is also approved for the reduction of MACE T2DM patients with multiple CV risk factors [13-15] (Table 2). The Liraglutide and Cardiovascular Outcomes in Type 2 Diabetes (LEADER) trial studied the cardiovascular effects of liraglutide in 9,340 patients with T2DM, aged 50 years or more with at least one $\mathrm{CV}$ coexisting condition, or aged 60 years or more with at least one $\mathrm{CV}$ risk factors. After a median follow up of 3.8 years, liraglutide was shown to be non-inferior to placebo in the primary outcomes of CV composite, which included first occurrence of death from $\mathrm{CV}$ causes, nonfatal MI, or nonfatal stroke. Liraglutide was also shown to be non-inferior in the expanded composite outcome measure that included coronary revascularization, or hospitalization for unstable angina or heart failure. In the composite outcome of microvascular nephropathy, the liraglutide group had a lower rate of events than placebo. Significant adverse events in the liraglutide group included a higher rate of acute gallstone disease, as well as nausea, vomiting, and diarrhea. Based on these results, the authors concluded that the rate of the first occurrence of death from $\mathrm{CV}$ causes, nonfatal MI, or nonfatal stroke among patients with T2DM was lower with liraglutide than with placebo [16].

Table 2: Cardiovascular Outcome Trials for Glucagon-Like Peptide 1 Receptor Agonists.

\begin{tabular}{|c|c|c|c|}
\hline Trial & LEADER16(Liraglutide) N=9,340 & $\begin{array}{l}\text { SUSTAIN-617(Semaglutide) } \\
\qquad \mathrm{N}=3,297\end{array}$ & REWIND18(Dulaglutide) N=9,901 \\
\hline \multirow{5}{*}{$\begin{array}{l}\text { Inclusion Criteria } \\
\text { (T2D) }\end{array}$} & Hgb A1c $\geq 7.0 \%$ & Hgb A1c $\geq 7.0 \%$ & Hgb A1c $\leq 9.5 \%$ \\
\hline & $\begin{array}{l}\text { If age } \geq 50, \geq 1 \text { of the following: } \\
\text { Cardiovascular, CKD, HF }\end{array}$ & $\begin{array}{l}\text { If age } \geq 50, \geq 1 \text { of the following: } \\
\text { Cardiovascular, CKD, HF }\end{array}$ & Max 2 oral agents +/- basal insulin \\
\hline & \multirow{3}{*}{ If age $\geq 60$, risk factors for vascular disease } & \multirow{3}{*}{$\begin{array}{l}\text { If age } \geq 60, \geq \text { of the following: } \\
\text { proteinuria, } \mathrm{LVH}, \mathrm{LV} \text { dysfunction, } \\
\text { ankle-brachial index }<0.9\end{array}$} & $\begin{array}{l}\text { Age } \geq 50 \text { with established vascular } \\
\text { disease }\end{array}$ \\
\hline & & & $\begin{array}{l}\text { Age } \geq 55 \text { with MI, LV hypertrophy, } \\
\text { eGFR }<60 \mathrm{~mL} / \mathrm{min} \text { or albuminuria }\end{array}$ \\
\hline & & & $\begin{array}{l}\text { Age } \geq 60 \text { with } 2 \text { of the following: } \\
\text { tobacco use, dyslipidemia, HTN, or } \\
\text { obesity }\end{array}$ \\
\hline \multirow[b]{4}{*}{ Pt Characteristics } & Average age: 64 years & Average age: 64.7 years & Average age: 66 years \\
\hline & Race: White (78\%) & Race: White (84.1\%) & Race: White (75.7\%) \\
\hline & Sex: Male (64\%) & Sex: Male (63\%) & Sex: Male (53\%) \\
\hline & $\begin{array}{l}\text { Baseline established CVD Any ( } 82 \%) \text {, } \\
\text { MI (31\%), stroke or TIA (16\%), prior } \\
\text { revascularization (39\%), >50\% stenosis of } \\
\text { coronary/carotid/ lower extremity artery } \\
\text { (25\%), symptomatic CHD (9\%), known } \\
\text { asymptomatic CHD }(27 \%)\end{array}$ & $\begin{array}{l}\text { Baseline IHD }(60.2 \%), \text { MI }(32.1 \%), \\
\text { HF }(21.9 \%) \text {, ischemic stroke }(10.8 \%), \\
\text { hemorrhagic stroke }(2.9 \%), \text { HTN } \\
(93.8 \%)\end{array}$ & $\begin{array}{l}\text { - Baseline cardiovascular disease } \\
(31 \%)\end{array}$ \\
\hline Duration & 3.8 years & 2.1 years & 5.4 years \\
\hline Baseline, End A1c & $8.7 \%, 7.7 \%$ & $8.7 \%, 7.3 \%(1 \mathrm{mg})$ & $7.3 \%, 6.7 \%$ \\
\hline Intervention & Liraglutide 1.8 mg SC daily & $\begin{array}{c}\text { Semaglutide } 0.5 \mathrm{mg} \text { or } 1 \mathrm{mg} \mathrm{SC} \\
\text { weekly }\end{array}$ & Dulaglutide 1.5 mg SC weekly \\
\hline $\begin{array}{l}\text { Primary composite } \\
\text { endpoint: (agent vs } \\
\text { placebo) }\end{array}$ & $\begin{array}{l}\text { First occurrence of CV mortality, nonfatal MI, } \\
\text { or nonfatal stroke } 13.0 \% \text { vs } 14.9 \% \text { (HR } 0.87 \text {; } \\
\qquad 95 \% \text { CI } 0.78-0.97 ; \mathrm{P}=0.01 \text { ) }\end{array}$ & $\begin{array}{l}\text { CV mortality, nonfatal MI, or nonfatal } \\
\text { stroke } 6.6 \% \text { vs } 8.9 \%(\text { HR } 0.74 ; 95 \% \\
\text { CI } 0.58-0.95 ; \mathrm{P}<0.001)\end{array}$ & $\begin{array}{c}\text { Primary efficacy composite (vascular } \\
\text { death, non-fatal MI, non-fatal stroke) } \\
12.0 \% \text { vs } 13.4 \% \text { (HR } 0.88 ; 95 \% \text { CI } \\
0.79-0.99 ; \mathrm{P}=0.026)\end{array}$ \\
\hline $\begin{array}{l}\text { Secondary endpoint: } \\
\text { CV death (agent vs } \\
\text { placebo) }\end{array}$ & $\begin{array}{l}4.7 \% \text { vs } 6.3 \% \text { (HR } 0.78 ; 95 \% \text { CI } 0.66-0.93 ; \\
\qquad P=0.007)\end{array}$ & $\begin{array}{c}2.7 \% \text { vs } 2.8 \% \text { (HR } 0.98 ; 95 \% \text { CI } 0.65 \text { - } \\
1.48 ; \mathrm{P}=0.92)\end{array}$ & $\begin{array}{c}6.4 \% \text { vs } 7.0 \%(\text { HR } 0.91 ; 95 \% \text { CI } 0.78- \\
1.06 ; \mathrm{P}=0.21)\end{array}$ \\
\hline $\begin{array}{l}\text { Secondary endpoint: } \\
\text { Stroke (agent vs } \\
\text { placebo) }\end{array}$ & $\begin{array}{l}3.4 \% \text { vs } 3.8 \% \text { (HR } 0.89 ; 95 \% \text { CI } 0.72-1.11 ; \\
\qquad P=0.30 \text { ) }\end{array}$ & $\begin{array}{c}1.6 \% \text { vs } 2.7 \%(\text { HR } 0.61 ; 95 \% \text { CI } 0.38- \\
0.99 ; P=0.04)\end{array}$ & $\begin{array}{c}2.7 \% \text { vs } 3.5 \%(\text { HR } 0.76 ; 95 \% \text { CI } 0.61- \\
0.95 ; P=0.017)\end{array}$ \\
\hline
\end{tabular}




\begin{tabular}{|c|c|c|c|}
\hline $\begin{array}{l}\text { Secondary endpoint: } \\
\text { HF hospitalization } \\
\text { (agent vs placebo) }\end{array}$ & $\begin{array}{l}4.7 \% \text { vs } 5.3 \% \text { (HR } 0.87 ; 95 \% \text { CI } 0.73-1.05 \\
\qquad \begin{array}{l}P=0.14)\end{array}\end{array}$ & $\begin{array}{c}1.3 \% \text { vs } 1.6 \% \text { (HR } 0.82 ; 95 \% \text { CI } 0.47- \\
1.44 ; \mathrm{P}=0.49)\end{array}$ & $\begin{array}{l}4.3 \% \text { vs } 4.6 \% \text { (HR } 0.93 ; 95 \% \text { CI } 0.77 \text { - } \\
\text { 1.12; } \mathrm{P}=0.46)\end{array}$ \\
\hline $\begin{array}{l}\text { Secondary endpoint: } \\
\text { Nephropathy (agent } \\
\text { vs placebo) }\end{array}$ & $\begin{array}{l}5.7 \% \text { vs } 7.2 \% \text { (HR } 0.78 ; 95 \% \text { CI } 0.67-0.92 ; \\
\qquad P=0.003 \text { ) }\end{array}$ & $\begin{array}{c}3.8 \% \text { vs } 6.1 \% \text { (HR } 0.64 ; 95 \% \text { CI } 0.46- \\
0.88 ; P=0.005)\end{array}$ & $\begin{array}{c}17.1 \% \text { vs } 19.6 \% \text { (HR } 0.85 ; 95 \% \text { CI } \\
0.77-0.93 ; \mathrm{P}=0.0004 \text { ) }\end{array}$ \\
\hline \multirow{3}{*}{$\begin{array}{l}\text { Other adverse effects } \\
\text { (agent vs placebo) }\end{array}$} & $\begin{array}{l}\text { Severe hypoglycemia: } 2.4 \% \text { vs } 3.3 \% \\
(\mathrm{P}=0.02)\end{array}$ & \multirow{3}{*}{$\begin{array}{l}\text { P-value was not provided for adverse } \\
\text { events }\end{array}$} & \multirow{3}{*}{$\begin{array}{l}\text { No statistical difference between } \\
\text { treatment groups in the rates of } \\
\text { adverse effects }\end{array}$} \\
\hline & Acute gallstones: $3.1 \%$ vs $1.9 \%(\mathrm{P}<0.001)$ & & \\
\hline & $\begin{array}{l}\text { Injection site reaction: } 0.7 \% \text { vs } 0.3 \% \\
\qquad(\mathrm{P}=0.002)\end{array}$ & & \\
\hline Authors' Conclusion & $\begin{array}{l}\text { Rate of 1st occurrence of death from CV } \\
\text { causes, nonfatal MI, or nonfatal stroke was } \\
\text { lower with liraglutide than with placebo }\end{array}$ & $\begin{array}{l}\text { Rate of CV death, nonfatal MI, or } \\
\text { nonfatal stroke was significantly } \\
\text { lower among patients receiving } \\
\text { semaglutide than with placebo }\end{array}$ & $\begin{array}{c}\text { The addition of dulaglutide to a T2DM } \\
\text { medical regimen reduced a composite } \\
\text { of cardiovascular outcomes over a 5- } \\
\text { year period }\end{array}$ \\
\hline
\end{tabular}

The Semaglutide and Cardiovascular Outcomes in Type 2 Diabetes (SUSTAIN-6) trial evaluated the CV effects of semaglutide in 3,297 patients with T2DM, aged 50 years or more with at least one $\mathrm{CV}$ coexisting condition, or aged 60 years or more with at least one $\mathrm{CV}$ risk factors. After a median follow up of 2.1 years, semaglutide was shown to be non-inferior to placebo in the primary composite outcome of CV composite, which included CV mortality, non-fatal MI, or non-fatal stroke. In the prespecified secondary outcomes that included revascularization and hospitalization for unstable angina or heart failure, as well as retinopathy and nephropathy, semaglutide was not demonstrated to differ significantly from placebo in reducing these events. Similar adverse events occurred in the semaglutide group compared to placebo. The authors concluded that the rate of CV death, nonfatal MI, or nonfatal stroke was significantly lower among T2DM patients with high CV risk while receiving semaglutide, when compared to placebo [17].

In the Dulaglutide and Cardiovascular Outcomes in Type 2 Diabetes (REWIND) trial, 9901 patients with T2DM, aged 50 years or more with established vascular disease, or age 55 or more with prior MI or cardiovascular comorbidities, or age 60 or more with at least two CV risk factors were followed for a median of 5.4 years. Dulaglutide was shown to be superior to placebo in the primary outcome of CV composite, which included vascular death, non-fatal MI, or non-fatal stroke. Of the composite cardiovascular outcomes, the lower rate of non-fatal stroke in the dulaglutide group primarily drove the statistical significance. In addition, patients who received dulaglutide also had a significantly lower rate of composite microvascular endpoint, particularly in the renal outcomes. Other safety outcomes for rates of discontinuation, pancreatitis, pancreatic cancer, thyroid cancer, serious GI events or any cancer were not significantly different from the placebo group. Based on the results and the relatively high percentage of patients without CV disease, the authors concluded that dulaglutide could be considered for the management of glycemic control in middleaged and older people with T2DM with either previous CVD or CV risk factors [18].

Although all three trials showed beneficial cardiovascular effects, there are also limitations. The REWIND trial had only $31 \%$ of its participants having a history of CV disease. Therefore, the results of this trial may be less applicable to the dulaglutide's CV benefits in the population who have had CV events.16 On the other hand, the LEADER and SUSTAIN-6 trials had a much higher percentage $(>80 \%)$ of patients with prior cardiovascular disease, suggesting stronger application in this population. However, the duration of the LEADER and SUSTAIN-6 trials were relatively short (3.8 and 2.1 years) compared to the REWIND trial (5.4 years), which makes the generalizability of their findings less, for their study populations consisting of higher percentage with established CV disease $[17,18]$ Another limitation of the REWIND trial is that more than $25 \%$ of participants were not taking dulaglutide at the time of their last visit, possibly diminishing the CV benefit of the study drug.18 While these studies focused on the CV effects of the GLP-1 RAs, the contribution to the overall CV benefits by the reduction of Hgb A1c was also not evaluated.

All three trials included participants with an approximate age of $65,75-84 \%$ white, and $53-64 \%$ males, which limits the external validity when considering patients for a GLP-1 RA, particularly those of a different race. Finally, the primary outcome for both SUSTAIN-6 and REWIND was only statistically significant as a composite, with only the individual component of nonfatal stroke being statistically significant. This largely impacts the applicability of semaglutide and dulaglutide, as they were not statistically significant in reducing the risk of other cardiovascular events, including myocardial infarction (MI) and heart failure (HF) [16-18].

\section{Discussion}

Sodium-glucose cotransporter 2 inhibitors can be used as an adjunct therapy in adult patients with T2DM to improve CV outcomes. Empagliflozin, as demonstrated in the EMPA-REG trial, appears to be beneficial in white, male patients with established CVD. Based on a high percentage of the study population having history of CVD, empagliflozin is the only SGLT2 inhibitor shown to reduce $\mathrm{CV}$ and overall mortality. Hence, empagliflozin is indicated to reduce the risk of $\mathrm{CV}$ death in adults with T2DM and established CVD $[6,9]$.

Due to the potential increased risk of amputation in canagliflozin as reported in the CANVAS trial, it is important that there is a thorough evaluation of the patient's history of 
amputation, peripheral vascular disease, or other risk factors prior to prescribing this medication. For T2DM patients who also have CKD, the CREDENCE trial presented a plausible benefit of kidney and CV protection with canagliflozin. While Canagliflozin reduces composite endpoints of CV mortality, MI, or stroke in T2DM patients with CVD, it doesn't significantly reduce these parameters individually. Canagliflozin is currently indicated to reduce the risk of MACE in adults with T2DM and established CVD as well as to reduce the risk of ESRD, doubling of serum creatinine, CV death, and hHF in adults with T2DM and diabetic nephropathy with albuminuria $[8,10,11]$.

The DECLARE TIMI-58 trial suggests dapagliflozin as a potential agent in lowering the rate of hospitalizations due to heart failure in T2DM patients. Dapagliflozin is considered neutral with regard to its impact on CV outcomes. The study population was $60 \%$ without hx of CVD but with high risk of CVD. Dapagliflozin is indicated to reduce the risk of hHF in adults with T2DM and established CVD or multiple CV risk factors. As demonstrated by the safety outcomes of the trials, it is important to ensure good urogenital hygiene and maintain hydration while receiving a SGLT2 inhibitor in order to minimize genital and urinary infections $[7,12]$.

Glucagon-like peptide 1 receptor agonists can also be recommended to type 2 diabetes patients as an additional agent to improve glycemic control, especially patients with established CVD or high CV risk. Liraglutide seems to have an edge over semaglutide and dulaglutide, in respect to it being the only GLP-1 RA to have demonstrated a reduction of CV and overall mortality in the LEADER trial, as well as potential reduction in nephropathy [16]. However, its shortcomings lie in its daily dosing frequency, compared to weekly dosing for semaglutide and dulaglutide. Semaglutide achieved a lower rate of primary composite outcome in the SUSTAIN-6 trial. Despite achieving a substantial glycosylated hemoglobin reduction of $1.4 \%$ in the study patients, semaglutide did not appear to have a significant difference in individual outcomes of CV mortality, nonfatal MI, or nonfatal stroke.17 Dulaglutide, as demonstrated in the REWIND trial, can potentially be used for primary prevention in patients that do not have established CVD. It also demonstrated a benefit in reducing the rate of nephropathy compared to placebo [18].

Liraglutide, semaglutide, and dulaglutide are all indicated to reduce the risk of MACE in adults with T2DM and established CVD in addition to improving glycemic control as an adjunct therapy. In addition to the indication for MACE reduction, dulaglutide is also FDA approved for the reduction of MACE in T2DM patients with multiple $\mathrm{CV}$ risk factors, based on the high percentage of patients in the REWIND trial who carried CV risks. Based on the safety outcomes in the three GLP-1 RA cardiovascular trials, there are black box warnings of increased thyroid C-cell tumor and recommendation against their use in patients who may have personal or family history or current thyroid tumors or multiple endocrine neoplasia type 2. Other precautions such as pancreatitis and diabetic retinopathy should also be considered before prescribing these agents. If GLP-1 RAs are used as part of the regimen for T2DM, it is important to make sure that there is no concomitant use of a dipeptidyl peptidase inhibitor, due to the shared mechanism of action with GLP-1 RA. Starting with the lower dose and titrate up to effective dosage is also recommended to minimize gastrointestinal side effects (nausea, vomiting, diarrhea). Lastly, patients should be reminded to rotate sites of injection to avoid injection site reactions [13-15].

\section{New Targets to Improve Cardiovascular Outcomes in the Management of T2DM}

Since the 2008 FDA guidance for industry entitled "Diabetes Mellitus - Evaluating Cardiovascular Risk in New Antidiabetic Therapies to Treat Type 2 Diabetes", pharmaceutical sponsors have shown that new type 2 diabetes drugs do not have excess ischemic cardiovascular risk, which has provided reassuring cardiovascular safety information for millions of diabetes patients. In light of the positive CVOT results, FDA is revisiting the recommendations of the December 2008 guidance and issued a new draft guidance on March 9th, 2020 entitled "Type 2 Diabetes Mellitus: Evaluating the Safety of New Drugs for Improving Glycemic Control," to look beyond ischemic cardiovascular disease, as well as for the inclusion of a broader scope of human subjects, such as older subjects and those with chronic kidney disease who may be more vulnerable to drug-related side effects.1 The current AACE/ACE and ADA diabetes treatment guidelines are also in accordance with the conclusions made from the recent CVOTs since their recommendations now support the addition of SGLT2i or GLP1 RA agents in T2DM patients who have $\mathrm{CV}$ risks or $\mathrm{CV}$ disease [4,5].

This review of studies performed on SGLT2i and GLP1 RA agents reminded us that the results were based heavily on composite endpoints, which together made it easier to achieve positive outcomes. However, this type of analysis does not allow clear distinction between individual endpoints, which may be driving the statistical difference. Emerged from these CVOTs are also questions surrounding the impact of reductions in hospitalizations for heart failure or unstable angina, as well as preservation of kidney function have on the overall cardiovascular outcomes in patients with T2DM. It has been suggested that CV biomarkers, such as $\mathrm{N}$-terminal pro-B-type natriuretic peptide and high sensitivity troponin, be used more in studies of new drugs for T2DM, due to the limitations of populations, size, and duration of the CVOT studies so far. The measurements of these biomarkers may be helpful in predicting future CV events, including heart failure and atherothrombotic events. Large clinical trials have shown the reduction in the risk of hospitalization for HF in T2DM patients with SGLT2i agents, however, most of the participants did not have HF at baseline. Therefore, the benefit with an SGLT2i treatment might have reflected the prevention of incident HF. To further evaluate the benefit of SGLT2i on hospitalization for HF or CV death, a recent trial entitled "Dapagliflozin in Patients with Heart Failure and Reduced Ejection Fraction" (DAPA-HF), aimed to determine the safety and efficacy of dapagliflozin in patients with 
heart failure and reduced ejection fraction of $40 \%$ or less, regardless of the presence or absence of T2DM. The authors concluded that in patients who had HF and a reduced ejection fraction, treatment with dapagliflozin resulted in lower risk of worsening HF or death from CV causes compared to placebo, regardless of presence or absence of diabetes [19].

\section{Conclusion}

The information in this article offers strategies when selecting treatments for patients with T2DM with cardiovascular risks and/or established disease. Clinicians may consider the overlapping effects on the heart, kidney while achieving glycemic control; keeping in mind that the medications that have been shown to have reduced cardiovascular events may do so due to multiple mechanisms. While a more aggressive approach should be taken with patients with T2DM to screen for and treat CV diseases, identification of diabetes and its treatment in patients with $\mathrm{CV}$ disease is also relevant.

\section{Acknowledgement}

None.

\section{Conflict of Interest}

No conflict of interest.

\section{References}

1. (2020) U.S. Food and Drug Administration. FDA Proposes Broad Approach for Conducting Safety Trials for Type 2 Diabetes Medications.

2. Smith RJ, Goldfine AB, Hiatt RH (2016) Evaluating the Cardiovascular Safety of New Medications for Type 2 Diabetes: Time to Reassess. Diab Care 39: 738-742.

3. Sattar N, Petrie MC, Zinman B, Januzzi JL (2017) Novel Diabetes Drugs and the Cardiovascular Specialist. J Am Coll Cardiol 69: 2646-2656.

4. (2020) Standards of Medical Care in Diabetes. Diabetes Care 43(Supplement 1): S2-S212.

5. Garber AJ, Handelsman Y, Grunberger G, Einhorn D, Abrahamson MJ, et al. (2020) Consensus Statement by the American Association of
Clinical Endocrinologists and American College of Endocrinology on the Comprehensive Type 2 Diabetes Management Algorithm - 2020 Executive Summary. Endocr Pract 26(1): 107-139.

6. Ridgefield CT (2020) Empagliflozin (Jardiance $\AA$ package insert). Boehringer Ingelheim Pharmaceuticals Inc.

7. Wilmington, DE (2020) Dapagliflozin (Farxiga ${ }^{\circledR}$ package insert). AstraZeneca Pharmaceuticals LP.

8. Titusville NJ (2020) Canagliflozin (Invokana® package insert). Janssen Pharmaceutical Inc.

9. Zinman B, Wanner C, Lachin JM, Fitchett D, Bluhmki E, et al. (2015) Empagliflozin, Cardiovascular Outcomes, and Mortality in Type 2 Diabetes (EMPA-REG OUTCOME). N Engl J Med 373: 2117-2128.

10. Neal B, Perkovic V, Mahaffey KW, de Zeeuw D, Fulcher G, et al. (2017) Canagliflozin and Cardiovascular and Renal Events in Type 2 Diabetes (CANVAS). N Engl J Med 377: 644-657.

11. Perkovic V, Jardine MJ, Neal B, Bompoint S, Heerspink HJL, et al. (2019) Canagliflozin and Renal Outcomes in Type 2 Diabetes and Nephropathy (CREDENCE). N Engl J Med 380: 2295-2306.

12. Wiviott SD, Raz I, Bonaca MP, Mosenzon O, Kato ET, et al. (2019) Dapagliflozin and Cardiovascular Outcomes in Type 2 Diabetes (DECLARE-TIMI 58). N Engl J Med 380: 347-357.

13. Plainsboro NJ (2019) Liraglutide (Victoza® package insert). Novo Nordisk Inc.

14. Plainsboro NJ (2020) Semaglutide (Ozempic® package insert). Novo Nordisk Inc.

15. Indianapolis IN (2020) Dulaglutide (Trulicity® package insert). Eli Lilly and Company.

16. Marso SP, Daniels GH, Brown-Frandsen K, Kristensen P, Mann JF, et al. (2016) Liraglutide and Cardiovascular Outcomes in Type 2 Diabetes (LEADER). N Engl J Med 375: 311-322.

17. Marso SP, Bain SC, Consoli A, Eliaschewitz FG, Jódar E, et al. (2016) Semaglutide and Cardiovascular Outcomes in Patients with Type 2 Diabetes (SUSTAIN-6). N Engl J Med 375: 1934-1944.

18. Gerstein HC, Colhoun HM, Dagenais GR, Diaz R, Lakshmanan M, et al. (2019) Dulaglutide and Cardiovascular Outcomes in Type 2 Diabetes (REWIND): A Double-blind, Randomised Placebo-controlled Trial. Lancet 394: 121-130.

19. McMurray JJV, Solomon SD, Inzucchi SE, Køber L, Kosiborod MN, et al. (2019) Dapagliflozin in Patients with Heart Failure and Reduced Ejection Fraction (DAPA-HF). N Engl J Med 381: 1995-2008. 